\title{
Transmission expansion planning considering multiple generation scenarios and demand uncertainty
}

\author{
Planeamiento de expansión de la transmisión considerando múltiples escenarios \\ de generación e incertidumbre en la demanda
}

Carlos Adrián Correa ${ }^{1} \quad$ Ricardo Bolaños ${ }^{2} \quad$ Antonio Escobar $^{3}$

Recibido 31 de enero de 2013, aceptado 9 de enero de 2014

Received: January 31, 2013 Accepted: January 9, 2014

\begin{abstract}
RESUMEN
El presente artículo presenta una metodología para resolver el problema del Planeamiento de la Expansión de la Transmisión (PET) cuando se consideran Múltiples Escenarios de Generación (MEG) e incertidumbre en la demanda. Los MEG conllevan a múltiples patrones de flujo de potencia, como resultado del ambiente competitivo existente en los sistemas eléctricos. Por lo tanto, en este trabajo, los diferentes patrones de flujo son tomados en cuenta para evitar congestión futura en la red de transmisión y así evitar futuros cortes de carga. La solución de este problema es obtenida mediante el uso del algoritmo genético especializado de Chu-Beasley, que incluye una nueva estrategia de programación no lineal para la población inicial, usando el método de punto interior. También se incluye una etapa de diversificación que esparce las soluciones en el espacio de búsqueda para aumentar la capacidad de convergencia.

A su vez, se tiene en cuenta la incertidumbre de la generación y la demanda mediante su inclusión en el modelo matemático, permitiendo variaciones en un rango determinado. Esta formulación está asociada con disminuciones importantes en los costos de los planes de expansión, cuando se comparan con los modelos tradicionales de generación y demanda fija.

Con esta metodología se encuentran planes de expansión para el sistema de Garver de 6 barras y el sistema IEEE de 24 barras, obteniendo un corte de carga nulo bajo cualquier escenario de generación futuro.
\end{abstract}

Palabras clave: Planeamiento de la transmisión, escenarios de generación, uncertainty, optimización, punto interior.

\begin{abstract}
This paper shows a methodology for solving the Transmission Expansion Planning Problem (TEPP) when Multiple Generation Scenarios (MGS) and demand uncertainty are considered. MGS lead to multiple power flow patterns, as a result of the competitive environment in power systems. In this work, the different flow patterns are taken into account, in order to avoid future congestion of the transmission network and thus avoiding future load shedding. The solution to this problem is obtained by a specialized Chu-Beasley Genetic Algorithm (CBGA) which includes a new initialization strategy using non-linear interior point. A diversification stage is also included to spread the solutions in the search space and increase convergence capability.

Generation and demand uncertainty are also considered in the mathematical model by allowing variations within a given range. This formulation allows for an important decrease in the cost of the expansion plans when compared to the traditional models with fixed generation and demand.
\end{abstract}

\footnotetext{
Universidad de La Salle. Cra 2 10-70. Bogotá, Colombia. E-mail: carcorrea@ unisalle.edu.co XM Filial de ISA. Calle 12 Sur 18-168. Medellín, Colombia. E-mail: rabolanos@xm.com.co

3 Universidad Tecnológica de Pereira. Complejo Educativo La Julita. Pereira, Colombia. E-mail: aescobar@utp.edu.co
} 
Expansion plans for the 6-bus Garver system and the IEEE-24 bus system are found with this methodology, obtaining zero load shedding under any future generation scenario.

Keywords: Transmission planning, generation scenarios, uncertainty, optimization, interior point.

\section{INTRODUCTION}

The TEPP consists on determining the required additions (transformers or lines) for the network so it can accomplish with the load growth constraints and the new available generation. When the expansion plan considers a unique horizon, the problem is considered to be static. On the other hand, when it considers multiple time periods, the approach is called multistage [1-5].

The mathematical model for this problem is nonlinear mixed integer, with considerable difficulty. It is part of the NP-complete (Non-Polynomial) problems due to the size of the solution space and is also a multimodal problem, which means that the presence of several local optima can lead the algorithm to be stuck at these points.

Another important feature in the planning process is the competitive environment present nowadays in the electric systems. In this scenario, transmission systems must adapt in such a way that the market is not affected by the network.

Different techniques have been used to solve the TEPP, such as linear programming [1, 6-7], dynamic programming [8], non-linear programming [9], mixed-integer programming [10], Benders [11-12], and also decomposition techniques as Branch-andBound [13].

Besides classical techniques, heuristic methods have also been satisfactorily used as an alternative. For instance, references [2,14-19] show how TEPP is solved using Simulated Annealing, Tabu Search, Genetic Algorithms and Particle Swarm Optimization. Other recent metaheuristic optimization techniques, such as frog leaping, immune systems, ant colony, chaos and bee colony algorithms, have also been used as referred in [3].

With the deregulation of electric markets and the growth of competitive schemes, new developments and approaches become necessary to face the TEPP and other common problems related to electric power systems.

These changes, lead to adjustments in TEPP models in order to include: congestion, annual costs, bilateral transactions, reliability and operation costs, among others [20-29]. The obtained expansion plans ensure equity to all market participants according to the considered information.

An alternative for treating the described problem is shown in [21]. In this work, a procedure for network reinforcement in a deregulated environment is designed, different patterns for power flow are considered and a decision scheme is incorporated to minimize the risk of the selected plan. The authors design and select a number of generation scenarios with a probability of occurrence for a future year.

This problem was also faced in [22] considering network security ( $\mathrm{N}-1$ contingency criteria). The way of solving this problem using a mono-objective approach is shown in [30].

Authors in [31] treated demand uncertainty by including demand as a variable in the mathematical model under a traditional planning scheme. The present methodology is based on the referenced paper for the treatment of uncertainty, but this work involves also MGS.

This paper proposes an approach for the TEPP when full open access for generators is considered. As a result, multiple power flow patterns need to be analyzed in order to obtain a feasible expansion plan. A specialized Chu-Beasley Genetic Algorithm is used to obtain a feasible expansion plan. The solution provide adequate operative conditions for any load flow pattern resulting from any dispatch scenario, ensuring zero load shedding values. This is achieved by considering the feasible Multiple Generation Scenarios (MGS) and also taking into account demand and generation as a variable within a narrow range. The proposed method is validated using the Garver system and the IEEE 24-bus RTS test system. 
The main contributions of this paper are listed below:

- Multiple generation scenarios are included in the planning process in order to obtain expansion plans capable of withstanding any dispatch scenario. This ensures that the transmission grid allows access equity for all generators.

- Variable generation and demand in each bus is considered in the model and comparative analysis with fixed values is carried out to show the impacts on reduction of the investment costs.

- A new initialization scheme to improve the CBGA performance is presented. This stage involves solving the relaxed DC model by using non-linear interior point method. In addition, a diversity strategy is included to cover more areas in the search space and accelerate convergence. This approach can be used for any metaheuristic technique, therefore, represents a tool for the operations research community.

\section{PROBLEM FORMULATION}

The TEPP is usually modeled using de DC equivalent, which is convenient for long term planning of active power. The DC model considering load shedding is the following [32]:

$$
\min v=\sum_{i, j \in \Omega} c_{i j} n_{i j}+\alpha \sum_{i \in N_{b}} r_{i}
$$

s.t.

$$
\begin{gathered}
S f+g+r-d=0 \\
f_{i j}-\gamma_{i j}\left(n_{i j}+n_{i j}^{0}\right)\left(\theta_{i}-\theta_{j}\right)=0 \\
\left|f_{i j}\right| \leq\left(n_{i j}+n_{i j}^{0}\right) \bar{f}_{i j} \\
0 \leq g \leq \bar{g} \\
0 \leq r \leq \bar{d} \\
\underline{d} \leq d \leq \bar{d} \\
0 \leq n \leq \bar{n}_{i j}
\end{gathered}
$$

$n_{i j}$ integer, $i, j \in \Omega$

Where $i j$ represents the branch between buses $i$ and $j$. Related to that branch, $c_{i j}, f_{i j}, \gamma_{i j}, n_{i j}, n_{i j}^{0}, \bar{f}_{i j}$ and $\bar{n}_{i j}$, represent respectively, the cost of a circuit, power flow, susceptance, number of added circuits, number of circuits in the base case, maximum power flow and the maximum number of circuits to be added; $S$, is the branch-node incidence matrix; $g, d$ and $r$, are the generation, demand and fictitious generation vectors, respectively; $f$, is a vector including the flows $f_{i j} ; \theta_{i}$ is the voltage angle in node $i ; \Omega$ is the set of candidate branches and $N_{b}$ is the number of buses.

Equations (2) and (3) represent the first and second Kirchhoff laws, respectively.

This problem is usually divided into two subproblems. One of them is called the investment problem and deals with the decision of where and how many circuits should be built. This investment proposal is then evaluated to determine electric feasibility and this evaluation is called operative problem. In this case, this problem is a Linear Programming (LP) problem, which is solved in this work using Interior Point Method (IPM) widely described in [33].

These two problems are iteratively solved until a feasible minimum cost plan is found.

\section{Transmission expansion planning considering multiple generation scenarios}

In order to take advantage of future generation and to supply necessary power for future loads, the transmission network must be reinforced based on the existence of deregulated markets. To face this new scheme, different load flow patterns must be taken into account according to the dispatch scenarios created by the market rules, by the changes in generation and demand, and by the availability of primary energy sources [20-23].

When considering the multiple load flow patterns, the different combinations of generated power in the electric system should be considered. These combinations depend on the cost of the MWh of each plant, weather conditions, the hourly demand, bids, and in general, the market rules of the specific location. Network should be able to deliver power without load shedding, hence, operative conditions must be evaluated for all possible generation scenarios, which is the purpose of the presented methodology. Along with the MGS, planners in a specific country should consider detailed market rules. 
For a given system with a specific demand $(d)$ and generation $(g)$ level, a generation scenario is defined as: any dispatch (within the generation limits) capable of meeting total demand, as follows:

$$
\sum_{i=1}^{n g} g_{i}=d_{\text {total }}
$$

Where $n g$ is the number of generators.

Given that the power is a real variable, there are infinite feasible scenarios. To simplify this problem, a representative set of scenarios is generated using the concept of feasible extreme scenario, which consists on setting the generators at the upper or lower limit. However, constraint 9 might not be met for a large number of combinations, given that several scenarios won't match the exact value of demand. Instead, total generation could be higher or lower so that the constraint is violated. To solve this issue, practical extreme scenarios are considered, by setting $n g-1$ generators in their upper/lower limits and leaving one generator to be set in an appropriate value to meet 9 [30].

In general, for an extreme scenario to be feasible, the following constraints must be met:

$$
\begin{gathered}
\sum_{i \in \Omega_{1}} g_{i}+\sum_{i \in \Omega_{2}} g_{i} \leq d_{\text {total }} \\
\sum_{i \in \Omega_{1}} g_{i}+\sum_{i \in \Omega_{2}} g_{i}+g_{k}^{\max } \geq d_{\text {total }}
\end{gathered}
$$

Where $\Omega_{1}$ and $\Omega_{2}$ are the subsets of generators in the lower and upper limits, respectively and $g_{k}^{\max }$ is the maximum generation level in bus $k$.

It is important to point that the number of possible scenarios is large, and is calculated as $n g \times 2^{n g-1}$.

\section{Mathematical model}

The formulation for the MGS problem with de DC model is as follows:

$$
\min v=\sum_{i, j \in \Omega} c_{i j} n_{i j}+\alpha \sum_{k=1}^{g s} r_{\text {total }}^{k}
$$

s.t.

$$
\begin{gathered}
S f^{k}+g^{k}+r_{g}^{k}=d \\
f_{i j}^{k}-\gamma_{i j}\left(n_{i j}+n_{i j}^{0}\right)\left(\theta_{i}^{k}-\theta_{j}^{k}\right)=0 \\
\left|f_{i j}^{k}\right| \leq\left(n_{i j}+n_{i j}^{0}\right) \bar{f}_{i j} \\
0 \leq g^{k} \leq \overline{g^{k}} \\
0 \leq r_{g}^{k} \leq d \\
0 \leq n \leq \bar{n}_{i j} \\
n_{i j} \text { integer, } i, j \in \Omega, k=1,2, \ldots, g s
\end{gathered}
$$

Where $g s$ is the number of all feasible extreme scenarios, $r_{g}^{k}$ is the vector of load shedding for a given generation scenario and $r_{\text {total }}$ is the load shedding for all generation scenarios.

The objective with this modeling is to obtain an expansion plan that can meet the demand under any generation scenario.

It is worth to notice that this mathematical model adds even more complexity, given that the number of variables increases when all feasible MGS are included, which is the case of this work.

\section{Demand uncertainty}

Future demand in the traditional planning process is considered as a datum and is a result of load forecasting for a given horizon. When uncertainty wants to be considered, it is possible to include it in the problem as a variable.

In this work, load in every node is considered as a variable, allowing the demand to vary within certain range of uncertainty. The objective function 12 , has to be rewritten including uncertainty in demand as shown:

$$
\min v=\sum_{i, j \in \Omega} c_{i j} n_{i j}+\alpha \sum_{k=1}^{g s} r_{\text {total }}^{k}-\delta \sum_{m} d_{m}
$$

It is considered that $\alpha>\delta$, indicating that load shedding is more severely penalized than supplied demand. These two factors impact the objective function as a linear combination of load shedding 
and demand, so any combination that meets $\alpha>\delta$ implies that more importance is given to alleviating 1 MW of load shedding than supplying one additional megawatt of load. The minus sign in 19 shows that when the investment plan allows meeting a larger demand, the objective function tends to reduce its value, and the plan becomes attractive.

Also a new constraint has to be added to the DC model in order to establish boundaries for demand at each bus:

$$
d_{\min } \leq d \leq d_{\max }
$$

The MGS problem is iteratively solved using a specialized Chu-Beasley Genetic Algorithm (CBGA) to analyze investment plans and interior point method to solve the operative problem.

The complete TEPP considering MGS and uncertainty, can be solved using non-linear programming such as IPM when $n_{i j}$ is treated as a continuous variable. In this work, a predictor corrector IPM is used to solve the continuous problem, which returns a number of lines for every generation scenario.

However, this investment plan is a vector containing real numbers, which is an unfeasible solution due to the integer nature of the variable $n_{i j}$.

Despite this unfeasibility, the solution of the nonlinear problem contains valuable information about the transmission paths with high possibility of being in the integer solution, and this information is used to generate feasible solutions through variations and combinations of the continuous plan. These solutions are used as part of the initial population for the genetic algorithm, while the remaining are randomly initialized as explained in the next section.

When the Genetic Algorithm (GA) starts evolving with the objective of minimizing cost, the different solutions are analyzed through a power flow in order to determine if the investment plan is able to meet the demand with its associated uncertainty. This operative condition is evaluated using IPM for the TEPP DC model.
Implementation of IPM for the linear and non-linear case is not described in this work but it is widely developed in [33-34].

\section{CHU-BEASLEY GENETIC ALGORITHM}

GAs have been widely used in optimization problems related to different disciplines, and have also been very successful in solving electrical problems with high combinatorial explosion $[18,31,35]$.

This work proposes a CBGA which presents several advantages when compared to the traditional GA, as keeping the size of the population constant to analyze only one solution in each generational cycle, decreasing the number of times that the objective function should be evaluated, which in this case means less load flows and less computational effort.

In addition, a solution is accepted into the population only when certain diversity criteria are met. This ensures that the solutions are located in different spots of the search space thus restricting homogeneous populations.

In this work, decimal codification was used for being appropriate for the TEPP [33] and the main steps are described in the following lines.

\section{Initialization of the population}

This is a very critical step for the success of the whole process, given that an adequate initialization can lead the algorithm towards areas where good quality solutions may be.

The presented approach differs from traditional methodologies where the linear transportation model or the Villasana-Garver-Salon methodology are used for initializing the population of a metaheuristic [22, $31,35]$. The proposed initialization scheme uses the information from the DC model when treating $n_{i j}$ as a continuous variable, improving the previous models given that non-linearity of the problem and both Kirchhoff laws are taken into account.

The process starts solving the non-linear problem of TEPP which returns real values for the additions $n_{i j}$, which might be important and with a high possibility of being in the final solution. Given the 
structure of the continuous problem, these paths have low cost to power transfer ratio, and are also relevant for alleviating load shedding problems. It is important to emphasize that one of the facts that guarantees the success of the CBGA is diversity, so, even though the continuous solution shows an interesting indication of important paths, it is not totally secure that all of the paths would be present in the final solution.

So said, this solution is used to generate only a few individuals, and the decision of adding a line where $n_{i j} \neq 0$ is taken randomly, and this way the individual has line additions in some of the paths meeting $n_{i j} \neq 0$.

After this step, the individual generation is carried out blocking the paths with $n_{i j} \neq 0$ and solving another non-linear problem. This leads to discovering other important paths that are not present in the base case and that have also certain importance in the planning process. The generation of the remaining individuals is then a cyclic process of blocking paths, running the non-linear problem and assigning additions, repeated a number of times depending on the population size.

\section{Diversity verification}

After the population is created, it is possible that some individuals have similar information, thus reducing diversity of the population and decreasing the possibilities of success of the GA.

To face this situation, a mechanism to verify diversity is developed, consisting on carrying out a comparison of each individual with the rest, to determine the quantity of paths with the same information. In this case, the similitude of one solution with another is determined by the existence or not of circuits in a path. To verify diversity between two solutions, the number of similar bits is limited to a maximum predetermined value $\left(\rho_{d i v}\right)$. To avoid substantial information loss from the continuous problem, this parameter should be set to a small value.

\section{Selection}

In the selection process two tournaments are carried out in order to select two parents. In each tournament there might be a variable number of parents, and if this number is high, it is clear that elitism is being prioritized and vice versa. In each tournament the individual with best fitness function earns a right as parent. This way, after two tournaments two parents would be ready for crossover stage.

\section{Crossover}

The crossover is done in the traditional way, using single-point logic. It should be clarified that in the CBGA there is no need for defining a crossover probability given that the population remains intact and only changes one of the individuals when certain diversity and optimality criteria, differing from the traditional GA which changes the entire population in every generation, so it turns out interesting in this approach that some solutions remain the same. After crossover of parents, two offspring solutions are generated and analyzed in order to keep the one with better fitness function.

\section{Mutation}

In this stage, addition of circuits is prioritized when the solution has high load shedding and vice versa. The probability of adding or removing circuits is given by $\rho_{\text {mut }}$.

\section{Optimality improvement stage}

Other feature of the presented CBGA is the inclusion of an improving stage, in which a solution resulting from mutation is analysed to determine if redundant circuits are present, by temporarily retiring them to find load shedding under this condition. If it decreases, then the circuit is permanently removed. With this procedure solutions with less level of unfeasibility and cost can be found. The drawback of this process is the increase of the computational effort.

\section{Promotion to the next generational cycle}

As mentioned before, preserving diversity will ensure that the GA can search in different areas and extract the best features, so they can be transmitted from generation to generation.

Hence, it is important to control the inclusion of new individuals into the population to avoid homogenization and decrease the chance of getting stuck in local optima.

Diversity verification at this point differs from the one carried out after the generation of initial population, because in this context all individuals are compared to each other to assure that all solutions have at least $\rho_{d i v}$ different bits. 
In this stage the comparison is done between the individual resulting from improvement and each one of the solutions in the population. If the candidate solution has more than $\rho_{d i v}$ different bits when compared to the others, it is classified as diverse, and non-diverse in the opposite case.

Figures 1 and 2 shows the complete CBGA algorithm and the scheme of promotion of a candidate solution to the next generational cycle.

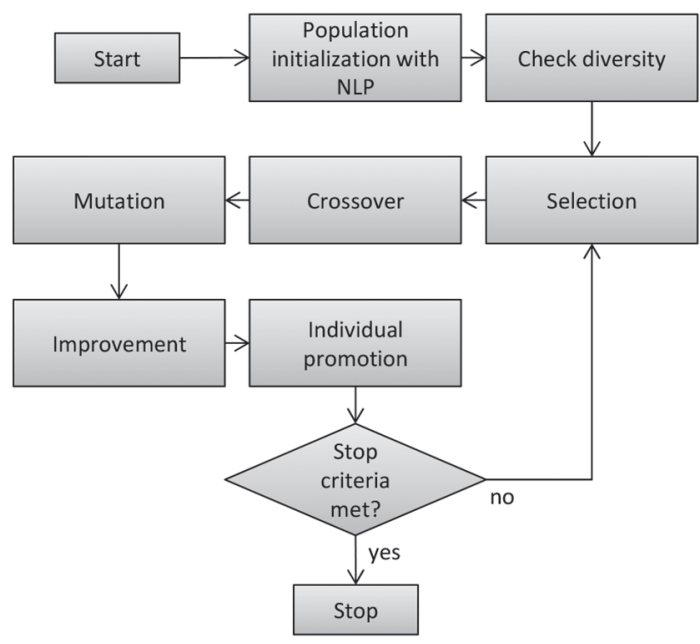

Figure 1. Scheme of the proposed CBGA.

\section{TEST RESULTS}

The problem formulated in (10)-(18), and including (19)-(20) for variable demand, is solved using the CBGA described in the previous section with the non-linear programming scheme for population initialization. Two test systems from the specialized literature were used: the 6-bus system proposed by Garver [6], and the IEEE 24-bus system. Network data for these systems can be found in $[11,21,32]$.

First, fixed demand model is investigated and the obtained expansion plans are shown for both systems. Then, circuit additions are shown for 5\% uncertainty in each bus for both generation and demand, demonstrating the increase in supplied power and the corresponding decrease in cost.

\section{Garver 6-bus system: fixed demand and generation rescheduling with MGS}

This network has 6 buses, 15 branches, a total demand of $760 \mathrm{MW}$, and a maximum of 5 parallel circuits to be added.

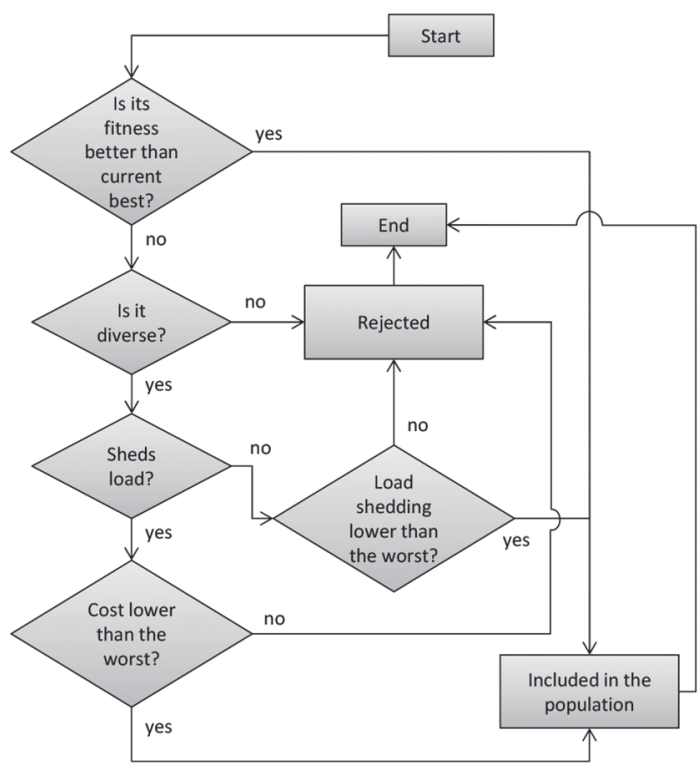

Figure 2. Promotion of a solution to the next generational cycle.

For this test system there are 4 feasible scenarios according to (10) and (11), which are detailed in Table 1. Scenario one, corresponds to generation in bus 1 at the minimum level, in bus 6 at the maximum, and generator in bus 3 is free to match the demand of $760 \mathrm{MW}$. Using the same logic, the other three generation scenarios are created with combinations of maximum, minimum levels, and one free generator.

Table 1. Feasible generation scenarios for Garver system.

\begin{tabular}{|c|r|c|c|}
\hline \multirow{2}{*}{ Scenario } & \multicolumn{3}{|c|}{ Generation (MW) } \\
\cline { 2 - 4 } & Bus 1 & Bus 3 & Bus 6 \\
\hline 1 & 0 & 160 & 600 \\
\hline 2 & 150 & 10 & 600 \\
\hline 3 & 0 & 360 & 400 \\
\hline 4 & 150 & 360 & 250 \\
\hline
\end{tabular}

As shown in the table, generation in buses 3 and 6 are important to create feasible scenarios. All of them have non zero generation value in those specific buses. It is clear that each scenario equals the necessary demand, $760 \mathrm{MW}$.

The parameters used for this system were the following: 100 individual population, $\rho_{d i v}=5$, $\rho_{\text {mut }}=4$. 
For this case, the algorithm finds an expansion plan with associated cost of $268 \times 10^{3}$ USD. The necessary additions in the transmission system are the following:

$$
n_{02-06}=4, n_{03-05}=2, n_{03-06}=1, n_{04-06}=2
$$

The investment plan has zero load shedding under any of the 4 scenarios, and total demand is $760 \mathrm{MW}$. As stated before, this expansion plan is able to withstand any generation dispatch combination of the 3 generators in the system, allowing network access equity to all market participants.

Garver 6-bus system: demand and generation uncertainty with MGS

When demand uncertainty is considered and the same algorithm parameters are used, the necessary additions require an investment of $238 \times 10^{3} \mathrm{USD}$, which represents a decrease of $30 \times 10^{3} \mathrm{USD}(11.2 \%)$ in cost when compared to the planning scheme with fixed demand. The circuit additions are the following:

$$
n_{02-06}=3, n_{03-05}=2, n_{03-06}=1, n_{04-06}=2
$$

It is clear that uncertainty generates a positive impact on the expansion plan by reducing total cost. The proposed plan has zero load shedding and total supplied demand increases to $798 \mathrm{MW}$, which is higher than the previous case.

\section{Garver 6-bus system: Basic planning scheme with rescheduling and MGS impact}

To analyze the impact of the MGS, the following lines will address the problem of neglecting scenarios during the planning process.

When the basic planning problem modeled in (1)-(8) is solved, the obtained plan has a cost of $110 \times 10^{3}$ USD and additions needed are $n_{3-5}=1$ and $n_{4-6}=3$. This expansion plan is only suitable under a unique generation scenario, but as discussed before, generation levels in each plant depend on different facts. If this expansion plan is subject to operative analysis for the 4 feasible generation scenarios, the resultant load shedding values are the ones in Table 2.

It can be concluded from this data, that the basic planning scheme it not suitable for future operation of the power system, due to the multiple load patterns
Table 2. Load shedding values for the basic planning scheme under MGS.

\begin{tabular}{|c|c|}
\hline Scenario & $\begin{array}{c}\text { Load } \\
\text { shedding } \\
\text { (MW) }\end{array}$ \\
\hline 1 & 300 \\
\hline 2 & 300 \\
\hline 3 & 120 \\
\hline 4 & 38.54 \\
\hline
\end{tabular}

when generators are dispatched, which is the case in real life systems. This fact explains the importance of solving the TEPP with MGS.

It is also worth noticing that including MGS increases the cost of the expansion plan, which also justifies the importance of considering demand uncertainty to partially alleviate extra costs, as already shown for Garver's system. Table 3 shows the trades-offs between the cost, load shedding, and supplied power, for each planning scheme.

Table 3. Summary of results for all planning schemes, Garver system.

\begin{tabular}{|l|c|c|c|}
\hline \multirow{2}{*}{ Parameter } & \multicolumn{3}{|c|}{ Planning Scheme } \\
\cline { 2 - 4 } & Basic & $\begin{array}{c}\text { MGS with } \\
\text { uncertainty }\end{array}$ & $\begin{array}{c}\text { MGS w/o } \\
\text { uncertainty }\end{array}$ \\
\hline $\begin{array}{l}\text { Cost } \\
\left(\times 10^{3} \text { USD) }\right.\end{array}$ & 110 & 1004 & 1330 \\
\hline $\begin{array}{l}\text { Load } \\
\text { shedding } \\
\text { under MGS } \\
\text { (accumulated) }\end{array}$ & 758 & 0 & 0 \\
\hline $\begin{array}{l}\text { Supplied } \\
\text { power }\end{array}$ & 760 & 798 & 760 \\
\hline
\end{tabular}

\section{IEEE 24-bus system: Fixed demand and} generation rescheduling

This test system has 24 buses, 41 branches, a total demand of $8550 \mathrm{MW}, 10$ generation buses, and a maximum of 3 added lines per branch.

The parameters used for this system were the following: 200 individual population, $\rho_{d i v}=9$, $\rho_{m u t}=6$. This system has 178 feasible scenarios, which leads to higher computational effort, and not shown in this paper due to space constraints. However, these scenarios can be found in [25].

The algorithm finds a minimum investment plan of $1330 \times 10^{6}$ USD. There is a special feature for 
this problem, given that seven alternative optimal solutions are found. For the sake of space, only one of the solutions is shown. The other 6 solutions can be found in [25].

$$
\begin{aligned}
& n_{01-02}=1, n_{01-05}=1, n_{03-24}=1, n_{04-09}=1 \\
& n_{05-10}=2, n_{06-10}=2, n_{07-08}=2, n_{08-09}=2 \\
& n_{08-10}=1, n_{09-12}=1, n_{10-11}=2, n_{10-12}=1 \\
& n_{11-13}=1, n_{11-14}=1, n_{12-23}=1, n_{14-16}=2 \\
& n_{15-21}=1, n_{15-24}=1, n_{16-17}=2, n_{16-19}=1 \\
& n_{17-18}=1, n_{20-23}=1, n_{21-22}=1, n_{01-08}=1
\end{aligned}
$$

This plan has zero load shedding and supplies a demand of $8550 \mathrm{MW}$ under any of the 178 scenarios.

\section{IEEE 24-bus system: Demand and generation uncertainty}

When 5\% variations in generation and demand are considered, an investment plan with associated cost of $1004 \times 10^{6}$ USD is obtained, with the following additions:

$$
\begin{aligned}
n_{01-02}=1, n_{01-05}=1, n_{03-09}=1, n_{03-24}=1 \\
n_{04-09}=1, n_{05-10}=1, n_{06-10}=2, n_{07-08}=3 \\
n_{08-09}=2, n_{08-10}=1, n_{09-11}=2, n_{09-12}=1 \\
n_{10-11}=1, n_{10-12}=1, n_{11-14}=1, n_{12-13}=1 \\
n_{14-16}=1, n_{15-24}=1, n_{16-17}=1, n_{16-19}=1 \\
n_{01-08}=1, n_{14-23}=1
\end{aligned}
$$

Considering uncertainty for the IEEE 24-bus leads to an increase in met demand of 8977.5MW. When comparing both cases, it is concluded that considering variable demand leads to a $326 \times 10^{6}$ USD $(24.5 \%)$ decrease in cost.

\section{IEEE 24-bus system: Basic planning scheme with rescheduling and MGS impact}

When only basic planning constraints are taken into account, the obtained expansion plan has a cost of $152 \times 10^{6}$ USD. This expansion plan is related to the following additions: $n_{06-10}=1, n_{07-08}=2, n_{10-12}=1$ and $n_{14-16}=1$. If the 178 generation scenarios are analyzed with these reinforcements, the minimum, average and maximum load shedding values are 144, 825 and $1488 \mathrm{MW}$ respectively, which turns this expansion plan into infeasible. This clearly shows that including MGS in the analysis is necessary for a proper planning of the future network in order to face different generation levels.

Table 4 summarizes the main information for all planning schemes and the differences for the most important variables: cost, load shedding and supplied demand.

Table 4. Summary of results for all planning schemes, IEEE 24-bus system.

\begin{tabular}{|l|c|c|c|}
\hline \multirow{2}{*}{ Parameter } & \multicolumn{3}{|c|}{ Planning Scheme } \\
\cline { 2 - 4 } & Basic & $\begin{array}{c}\text { MGS with } \\
\text { uncertainty }\end{array}$ & $\begin{array}{c}\text { MGS w/o } \\
\text { uncertainty }\end{array}$ \\
\hline $\begin{array}{l}\text { Cost } \\
\left(\times 10^{6} \text { USD) }\right.\end{array}$ & 152 & 1004 & 1330 \\
\hline $\begin{array}{l}\text { Load } \\
\text { shedding } \\
\text { under MGS } \\
{[\text { MW] }} \\
\text { (average })\end{array}$ & 825 & 0 & 0 \\
\hline $\begin{array}{l}\text { Supplied } \\
\text { power [MW] }\end{array}$ & 8550 & 8977.5 & 8550 \\
\hline
\end{tabular}

\section{CONCLUSIONS}

A Chu-Beasley Genetic Algorithm was proposed to solve the TEPP when MGS are taken into account and uncertainty in demand and generation is considered. MGS allow evaluating all possible power flow patterns according to different generation scheduling scenarios. Uncertainty gives more flexibility to the planning process and allows savings for in the investment plan. Results show that for both test systems, total cost is reduced and also more demand can be supplied. For Garver's system, there is an $11.2 \%$ cost reduction, and a $24.5 \%$ reduction is achieved for the IEEE 24-bus system.

The evolutionary algorithm is initialized after solving the continuous DC model with the non-linear interior point. This initialization scheme allows leading the algorithm towards good quality regions, given that the relaxed version of the DC model complies with both Kirchhoff laws. The specialized CBGA reduces computational effort and preserves diversity during the optimization process.

MGS allow planning an adequate transmission system to meet future demand and reduce generation restrictions due to network constraints. In this work, the presented expansion plans can handle any 
generation dispatch resulting from the competitive market scheme. In concrete, the expansion plans for Garver system withstand the total of 4 feasible scenarios, and accordingly, 178 scenarios for the IEEE 24-bus system.

Investment costs are higher when MGS are considered, given that all feasible generation scenarios are analyzed. Another approach can be based on a limited number of generation scenarios according to the most possible dispatch patterns. This would reduce the number of scenarios, and therefore, would lead to lower cost plans and lower computational effort.

\section{REFERENCES}

[1] R. Villasana, L.L. Garver and S.J. Salon. "Transmission network planning using linear programming". IEEE Transactions on Power Apparatus and Systems. Vol. PAS-104, Issue 2, pp. 349-356. 1985. ISSN: 0018-9510. Doi: 10.1109/TPAS.1985.319049.

[2] S.P. Torres and C.A. Castro. "Parallel particle swarm optimization applied to the static Transmission Expansion Planning problem", 2012 Sixth IEEE/PES Transmission and Distribution: Latin America Conference and Exposition. Montevideo, Uruguay. 2012.

[3] R. Hemmati, R.A. Hooshmand and A. Khodabakhshian. "State-of-the-art of transmission expansion planning: Comprehensive review". Renewable and Sustainable Energy Reviews. Vol. 23, pp. 312-319. 2013. ISSN: 1364-0321. Doi: 10.1016 /j.rser.2013.03.015.

[4] H. Zhang, V. Vittal, G. Heydt and J. Quintero. "A mixed-Integer linear programming approach for multi-Stage security-constrained transmission expansion planning”. IEEE Transactions on Power Systems. Vol. 27, Issue 2, pp. 1125-1133. 2012. ISSN: 08858950. Doi: 10.1109/TPWRS. 2011.2178000.

[5] M.C. da Rocha and J.T. Saraiva. "A discrete evolutionary fPSOg based approach to the multiyear transmission expansion planning problem considering demand uncertainties". International Journal of Electrical Power and Energy Systems. Vol. 45, Issue 1, pp. 427442. 2013. ISSN: 0142-0615. Doi: 10.1016/j. ijepes.2012.09.009.
[6] L.L. Garver. "Transmission network estimation using linear programming". IEEE Transactions on Power Apparatus and Systems. Vol. PAS-89, Issue 7, pp. 16881697. 1970. ISSN: 0018-9510. Doi: 10.1109/ TPAS.1970.292825.

[7] K.J. Kim, Y.M. Park and K.Y. Lee. "Optimal long term transmission expansion planning based on maximum principle". IEEE Transactions on Power Systems. Vol. 3, Issue 4, pp. 1494-1501. 1988. ISSN: 08858950. Doi:10.1109/59.192958.

[8] Y.P. Dusonchet and A.H. El-Abiad. "Transmission planning using discrete dynamic optimization". IEEE Transactions on Power Apparatus and Systems. Vol. PAS-92, Issue 4, pp. 1358-1371. 1973. ISSN: 00189510. Doi: 10.1109/TPAS.1973.293543.

[9] H.K. Youssef and R. Hackam. "New transmission planning model". IEEE Transactions on Power Systems. Vol. 4, Issue 1, pp. 9-18. 1989. ISSN: 0885-8950. Doi: $10.1109 / 59.32451$.

[10] L. Bahiense, G.C. Oliveira, M. Pereira and S. Granville. "A mixed integer disjunctive model for transmission network expansion". IEEE Transactions on Power Systems. Vol. 16, Issue 3, pp. 560-565. 2001. ISSN: 0885-8950. Doi: 10.1109/59.932295.

[11] R. Romero and A. Monticelli. "A zero-one implicit enumeration method for optimizing investment in transmission expansion planning". IEEE Transactions on Power Systems. Vol. 9, Issue 3, pp. 1385-1391. 1994. ISSN: 0885-8950. Doi:10.1109/59.336126.

[12] S. Binato, M. Pereira and S. Granville. "A new benders decomposition approach to solve power transmission network design problems". IEEE Transactions on Power Systems. Vol. 16, Issue 2, pp. 235-240. 2001. ISSN: 0885-8950. Doi: 10.1109/59.918292.

[13] S. Haffner, A. Monticelli, A. Garcia, J. Mantovani and R. Romero. "Branch and bound algorithm for transmission system expansion planning using a transportation model". Proceedings of the IEE Generation, Transmission and Distribution. Vol. 147, Issue 3, pp. 149-156. 2000. ISSN: 13502360. Doi:10.1049/ipgtd:20000337.

[14] R. Gallego, A.B. Alves, A. Monticelli, and R. Romero. "Comparative studies 
of non-convex optimization methods for transmission network expansion planning". IEEE Transactions on Power Systems. Vol. 13, Issue 3, pp. 822-828. 1998. ISSN: 0885-8950. Doi:10.1109/59.708680.

[15] R. Gallego, A. Monticelli and R. Romero, "Tabu search algorithm for network synthesis". IEEE Transactions on Power Systems. Vol. 15, Issue 2, pp. 490-495. 2000. ISSN: 0885-8950. Doi: 10.1109/59.867130.

[16] R.A. Gallego. "Planejamento a longo prazo de sistemas de transmissao usando tecnicas de otimizacao combinatorial". Ph.D. dissertation. FEEC DSEE Unicamp. Campinas, Brasil. 1997.

[17] J. Silva and H.A. Gil. "Transmission planning based on heuristic methods". Proc. VII Symposium of Specialists in Electric Operation, Expansion and Planning. Curitiba, Brasil. 2000.

[18] J.M. Arroyo and F.J. Fernandez. "Application of a genetic algorithm to $n-K$ power system security assessment". International Journal of Electrical Power and Energy Systems. Vol. 49, pp. 114-121. 2013. ISSN: 01420615. Doi:10.1016/ j.ijepes.2012.12.011.

[19] P. Murugan. "Modified particle swarm optimisation with a novel initialization for finding optimal solution to the transmission expansion planning problem". Generation, Transmission Distribution, IET. Vol. 6, Issue 11, pp. 1132-1142. 2012. ISSN: 17518687. Doi:10.1049/iet-gtd.2012.0183.

[20] R. Baldick and E. Kahn. "Transmission planning issues in a competitive economic environment". IEEE transactions on power systems. Vol. 8, Issue 4, pp. 1497-1503. 1993. ISSN: 0885-8950. Doi:10.1109/59.260951.

[21] R. Fang and D. Hill. "A new strategy for transmission expansion in competitive electricity markets". IEEE Transactions on power systems. Vol. 18, Issue 1, pp. 374380. 2003. ISSN: 0885-8950. Doi: 10.1109/ TPWRS.2002.807083.

[22] M. Rider, I. de J. Silva, R. Romero, A. Garcia and C. Murari. "Transmission network expansion planning in full open market considering security constraints". 2005 IEEE Power Tech. Russia. 2005.

[23] S. de la Torre, A.J. Conejo and J. Contreras, "Transmission expansion planning in electricity markets". IEEE transactions on power systems. Vol. 23, Issue 1, pp. 238248. 2008. ISSN: 0885-8950. Doi: 10.1109/ TPWRS.2007.913717.

[24] J. Aguado, S. de la Torre, J. Contreras, A. Conejo and A. Martinez. "Market-driven dynamic transmission expansion planning". Electric Power Systems Research. Vol. 82, Issue 1, pp. 88-94. 2012. ISSN: 0378-7796. Doi: 10.1016/j.epsr.2011.09.001.

[25] A.A. Foroud, A.A. Abdoos, R. Keypour and M. Amirahmadi. "A multiobjective framework for dynamic transmission expansion planning in competitive electricity market". International Journal of Electrical Power and Energy Systems. Vol. 32, Issue 8, pp. 861-872. 2010. ISSN: 0142-0615. Doi: 10.1016/j.ijepes.2010.01.027.

[26] P.S. Georgilakis. "Market-based transmission expansion planning by improved differential evolution". International Journal of Electrical Power and Energy Systems. Vol. 32, Issue 5, pp. 450-456. 2010. ISSN: 0142-0615. Doi: 10.1016/j.ijepes.2009.09.019.

[27] H. Gunnaasankaraan, A. Viswanath, K. Mahata and L. Goel. "Transmission planning by minimizing curtailment of market transactions". Electric Power Systems Research. Vol. 101, pp. 1-8. 2013. ISSN: 03787796. Doi: 10.1016/ j.epsr.2013.02.010.

[28] R.C. Leou. "A multi-year transmission planning under a deregulated market". International Journal of Electrical Power \& Energy Systems. Vol. 33, Issue 3, pp. 708714. 2011. ISSN: 0142-0615. Doi: 10.1016/j. ijepes.2010.11.020.

[29] Y. Wang, H. Cheng, C. Wang, Z. Hu, L. Yao, Z. Ma and Z. Zhu. "Pareto optimalitybased multi-objective transmission planning considering transmission congestion". Electric Power Systems Research. Vol 78, Issue 9, pp. 1619-1626. 2008. ISSN: 0378-7796. Doi: http://dx.doi.org/10.1016/j.epsr.2008.02.00.

[30] A. Escobar, R. Romero and R. Gallego. "Transmission expansion planning considering multiple generation scenarios". IEEE PES Transmission and Distribution. Bogota, Colombia. 2008.

[31] I. Silva, M.J. Rider, R. Romero and C.A.F. Murari. "Transmission network expansion planning considering uncertainty in demand". 
IEEE transactions on Power Systems. Vol. 21, Issue 4, pp. 1565-1573. 2006. ISSN: 08858950. Doi: 10.1109/TPWRS.2006.881159.

[32] R. Romero, A. Monticelli, A. Garcia and S. Haffner. "Test systems and mathematical models for transmission network expansion planning". Generation, Transmission and Distribution, IEE Proceedings. Vol. 149, Issue 1, pp. 27-36. 2002. ISSN: 1350-2360. Doi: 10.1049/ip-gtd:20020026.

[33] C. Correa. "Planeamiento multiobjetivo de la expansión de la transmisión considerando múltiples escenarios de generación". Master's thesis. Universidad Tecnológica de Pereira. Pereira, Colombia. 2008.

[34] I. Sanchez, R. Romero, J. Mantovani and M. Rider. "Transmission expansion planning using the dc model and nonlinearprogramming technique". IEE Proceedings Generation, Transmission \& Distribution. Vol. 152, Issue 6. 2005.

[35] L. Gallego, M. Rider, R. Romero and A. Garcia. "A specialized genetic algorithm to solve the short term transmission network expansion planning". 2009 IEEE PowerTech. Bucharest, Romania. 2009. 